Brit.J. prev. soc. Med. (1965), 19, 143-150

\title{
PSYCHIATRIC MORBIDITY AMONG STUDENTS
}

\author{
BY \\ CECIL B. KIDD \\ Medical Research Council Unit for Research on the Epidemiology of Psychiatric Illness, Department of Psychological \\ Medicine, University of Edinburgh*
}

Information regarding the frequency and concomitants of mental ill-health among students is accumulating at every university, but there is a special need for a better understanding of the factors involved and the relative importance of each. Much of the difficulty in establishing the characteristics of students who have psychiatric disorders stems from two sources: by no means all students who have these conditions seek advice for them, and for those who do consult, there is a lack of uniformity in definition of criteria for illness. Morbidity rates based on numbers of patients who have clearly definable psychiatric disorders generally give an index only of the extent of severe illness among students. These figures rarely include those who consult with minor psychological complaints, yet the important role played by minor emotional disturbances in determining the happiness, adjustment, and efficiency of students suggests that the numbers of those who have this cannot be ignored. Estimates of the prevalence of psychiatric disorders among students vary from 1 to 20 per cent. of all at risk and in proportion to the stringency of the criteria used.

Prevalence studies that have provided information relevant to the characteristics of students who have psychiatric disorders largely fall into four main categories:

(1) Some have been concerned to obtain a prevalence figure for psychiatric disorders in relation to the number of students attending university health services during the academic year (Davy, 1960; Johnston, 1962; JuelJensen, 1962; Malleson, 1954, 1959b, 1961; Still, 1961 ; Verney, 1961).

(2) Some university health services have held questionnaire inquiries to assess the incidence of psychological complaints among students (Davy, 1957; Grant, 1954; Malleson, 1959a).

(3) Some have provided details of psychiatric disorders presenting among students who attend voluntarily for health examinations (Malleson, 1958; Parnell, 1947; Pemberton, 1948).

- Present address, Department of Mental Health, University of Aberdeen.
(4) Some have provided details of the extent of usage of their psychiatric services by students (Carroll and Jones, 1944; Mechanic, 1961; Read, 1954; Sinclair-Gieben, 1961; Snyder, 1962).

In these studies possible indicators towards proneness to psychiatric disorders have been cited among social and demographic, economic, medical, psychological, and educational factors in the students' backgrounds as well as provocative factors experienced in adjusting to university life, particularly during their early terms. A uniform finding is that psychiatric disorders are not distributed evenly among students at different stages of university training: proportionately more first-year students than others have been reported to have psychiatric disorders (Gifford, 1961; Malleson, 1961; SinclairGieben, 1961 ; Verney and Robertson, 1948).

Most prevalence studies have been retrospective and have considered only students who have been ill. Some investigators have examined certain characteristics of ill students and compared them with the same features in a control group of healthy students, but these useful reports are few. Little is known about the mental health of students who live locally and do not come to the notice of the university health physicians. While they are few in number at the predominantly residential universities, they account for about one-third of all students at the provincial and Scottish universities. Thus, the available data describe the characteristics of only a proportion of those who are at risk, and concentrate on those who have been ill.

Clinical studies can merely suggest factors that influence the prevalence of psychiatric disorders among students, although they do provide indications about where to expect high rates of illness among the student population. To identify those who are prone to illness, it is necessary to carry out an epidemiological study which aims, by prospective inquiry, to examine the distribution of psychiatric disorders within a total student population and the factors governing them. This approach allows identification of the significant attributes of students who are prone to develop psychiatric disorders, and 
is an essential step in designing a rational service for the prevention of student breakdown.

The aim of this investigation was to determine the factors that most influenced the prevalence of psychiatric disorders among a total new entry of university students.

\section{Method \\ IDENTIFICATION OF THE COHORT}

The first stage of the study consisted in a review of the literature on student mental illness and student wastage to identify characteristics in the background of the student which might have a bearing on his mental health and which could be measured at his point of entry to the university. These comprised two main groups:

(a) Objective and factual data about the student's life, background, and experience;

(b) His subjective opinions and attitudes, suitable for recording within the framework of a structured questionnaire.

Earlier studies have demonstrated or suggested a wide variety of factors concerned with student breakdown:

Personal, Social, and Demographic.-Age, sex, social class, marital status, and religious affinities were commonly cited.

Ethnic.-Differences in rates of illness between overseas and British students, and the influences of language, culture, colour, and cultural transition.

Parental and Familial.-Influence of the broken home or of disharmony in the home, parental pressures, parental attitudes, and their influence on the student's motivation and adjustment in university life.

Economic.-Influence on illness of financial hardship, marital responsibilities, and the financial strain imposed on the student's family by his education.

Medical.-Previous health of student, his self-rating of health, loss of schooling through illness, previous illnesses and frequency of consultations with his doctor.

Pre-university School Experience.-Differences in progress (and therefore possibly in psychological health) between those from different types of schools and different modes of examination entry, influence on the student's mental health at university of his having been or not been an all-rounder, good at every aspect of the school's activities.

The University Situation.-Different rates of illness in different faculties, and in different types of courses living arrangements while at university, suggesting differences in rates of illness amongst those living at home as opposed to those in digs or in halls or in flats, previous experience of living away from home, and the reported strain of daily commuting.

For each of the factors that were taken from the literature in this way a hypothesis was constructed; for example "there is an association between having a working class background and developing psychiatric disorder while at university". The aim here was to examine the social class distribution of the ill students against the social class distribution of all students to determine if an association did truly exist.

A questionnaire designed to ascertain the presence or absence of these factors was given to a total cohort of first-year students at the University of Edinburgh who were entering university life for the first time at the beginning of the survey year. The final composition of the cohort, adjusted by referring to the criteria for inclusion and to a nominal matriculation roll, was 1,555 students, of whom 981 were men and 574 were women. There was only one refusal.

\section{CAse Identification}

A "mid-survey" inquiry, directed towards both students and their doctors, was carried out at the end of the first 3 months of the period of scrutiny. It sought permission from the students for the author to question their doctors about them for the purposes of this study. Only four students withheld their consent. It determined the extent to which students had consulted doctors other than those with whom they were registered. It showed to what extent doctors were likely to co-operate in providing data (judged by their response to this "mid-survey" study), and finally it demonstrated the amount of agreement between students and doctors about consultations made by the one with the other. This inquiry made it possible to decide the best methods for detecting those who had developed psychiatric disorders and on suitable criteria to be used for case identification.

At the end of the survey year a questionnaire was sent to each member of the cohort, asking whether, during the academic year, he had been "emotionally or nervously unwell", to which only the answer "Yes" or "No" was required. 1,520 questionnaires were sent out and 1,505 (99 per cent.) were completed, some being returned only after repeated requests. Questionnaires were not sent to 35 students: 31 who had left the university (mostly non-graduating students who had not intended to remain for a full academic year), two who had died, and two whose addresses could not be traced. This inquiry provided an arbitrary measure of self-declaration of illness by the cohort.

The prevalence of medically-detected psychiatric disorders among the cohort was next determined. Two levels of case identification were used. The first comprised inquiry at all psychiatric services within the city of Edinburgh and the South-East region of 
Scotland to determine whether any member of the cohort had been seen by a psychiatrist, as an inpatient or as an out-patient, during the academic year. Clinical and referral details were sought in respect of these students. The second level of inquiry determined whether any member of the cohort had consulted his own doctor (whether at the University Health Service or one of the $\mathbf{2 5 7}$ general practitioners with whom those not attending the Service were registered) for a psychiatric disorder of defined severity.

The working definition of illness adopted was that proposed by Backett, Shaw, and Evans (1953), namely "a disturbance of a patient's health that is reflected in at least one consultation".

It was hoped that three aims could be realized in choosing criteria for illness in this study. The criteria should be clear and meaningful in the light of the general practitioner's experience of both major and minor psychiatric disorders: the criteria should be brief, explicit, and able to be applied readily in considering a patient; subsequent workers should be in no doubt as to the nature and variety of illness included within the criteria, both for interpretation of the findings and as a basis for comparative studies. The classification described by Kessel (1960) meets these three aims, and had already proved meaningful in a previous general practice survey. The only modification employed for this survey was to exclude mental sub-normality and the senile dementias, since these would not be found among students.

Of the cohort, 956 students (584 men, 372 women) were registered with the University Health Service and 39 students ( 24 men, 15 women) were attending the Service although not formally registered. 528 students ( 353 men, 175 women), mostly those living at home, were registered with 257 general practitioners in Edinburgh and its environs. The medical attendants of 32 students ( 20 men, 12 women) were not known.

The five physicians at the University Health Service and the 257 general practitioners were personally contacted in respect of the students registered with their practices. No inquiry was made about any of the few students who had objected to the survey. The purposes of the survey, the students' permission for these inquiries, and the operational criteria for identification of a case were discussed: such discussion was intended only to guide and in each instance the final decision was made by the student's own doctor. This investigation provided a period prevalence rate for psychiatric disorders of defined severity among the total cohort of all first-year students at risk during one academic year.

\section{RESULTS}

The distribution of the cohort by sex and age is shown in Table I and by faculty of study in Table II.

TABLE I

DISTRIBUTION OF COHORT BY SEX AND AGE AT ENTRY TO UNIVERSITY

\begin{tabular}{c|c|c|c|c}
\hline \multirow{2}{*}{$\begin{array}{c}\text { Age } \\
\text { Group }\end{array}$} & \multicolumn{2}{|c|}{ Men } & \multicolumn{2}{|c}{ Women } \\
\cline { 2 - 4 } (yrs) & No. & Per cent. & No. & Per cent. \\
\hline $17-$ & 129 & $13 \cdot 1$ & 104 & $18 \cdot 1$ \\
$18-$ & 456 & 46.5 & 297 & 51.7 \\
$19-$ & 171 & 17.4 & 89 & 15.5 \\
$20-$ & 49 & 5.0 & 41 & 7.1 \\
$21+$ & 176 & 17.9 & 43 & $7 \cdot 5$ \\
\hline All Ages & 981 & 100.0 & 574 & $100 \cdot 0$ \\
\hline
\end{tabular}

TABLE II

DISTRIBUTION OF COHORT BY FACULTY OF STUDY

\begin{tabular}{|c|c|c|c|c|c|}
\hline \multicolumn{3}{|c|}{ Faculty } & \multirow{2}{*}{$\begin{array}{r}\text { Men } \\
223 \\
8 \\
13 \\
2 \\
53\end{array}$} & \multirow{2}{*}{$\begin{array}{r}\text { Women } \\
339 \\
2 \\
3 \\
12 \\
3\end{array}$} & \multirow{2}{*}{$\begin{array}{c}\begin{array}{c}\text { All } \\
\text { Students }\end{array} \\
562 \\
10 \\
16 \\
14 \\
56\end{array}$} \\
\hline Arts & $\begin{array}{l}\text { Arts ... } \\
\text { Architecture } \\
\text { Commerce } \\
\text { Social Studies } \\
\text { Accountancy }\end{array}$ & & & & \\
\hline Music & $\ldots$ & . & 1 & 9 & 10 \\
\hline Law & . & $\ldots$ & 59 & 11 & 70 \\
\hline Medicine & $\begin{array}{l}\text { Medicine } \\
\text { Dentistry } \\
\text { Veterinary }\end{array}$ & $\begin{array}{l}\ldots \\
\cdots\end{array}$ & $\begin{array}{r}127 \\
40 \\
47\end{array}$ & $\begin{array}{r}31 \\
13 \\
6\end{array}$ & $\begin{array}{r}158 \\
53 \\
53\end{array}$ \\
\hline Science & . & . & 369 & 88 & 457 \\
\hline \multicolumn{2}{|c|}{$\begin{array}{l}\text { Non-Graduating } \\
\text { (irrespective of faculty) }\end{array}$} & . & 39 & 57 & 96 \\
\hline Total & $\ldots$ & $\ldots$ & 981 & 574 & 1,555 \\
\hline
\end{tabular}

Most of the students, and proportionately more women than men, were aged 18 years and under 19 on entry to the university. Proportionately more men than women were aged 21 years and over on entry. Proportionately twice as many women as men were studying in the Faculty of Arts, while the reverse was true for those studying Science. 96 students were taking non-graduating courses, mainly in the Faculty of Arts : most of these were overseas students. Almost two-thirds of the students were Scottish, and of these more than half came from Edinburgh and its environs. Less than one-third came from England, and very few from Wales and Northern Ireland. 162 students $(10.4$ per cent. of the cohort) came from the Commonwealth or foreign countries, the greatest numbers from the USA, West Germany, the West Indies, and Nigeria.

Of the 1,555 students who comprised the cohort, 178 (99 men, 79 women) declared by questionnaire response that during the period of scrutiny they had been "emotionally or nervously unwell". Expressed 
as percentages, the rates for self-declaration of illness among the total cohort were 10.0 per cent. for men and 13.8 per cent. for women. Women students declared emotional illness significantly more often than did men $\left(\chi^{2}=4.39 ; \mathrm{P}<0.05 ; 1\right.$ d.f. $)$.

Of all at risk, during the period of scrutiny two were admitted to a mental hospital, a further sixteen had consulted a psychiatrist, and, in all, 172 students ( 88 men, 84 women) who had consulted a doctor were diagnosed by him to have a psychological condition. The one (academic) year period prevalence rate for psychiatric disorders among the cohort was 9.0 per cent. for men and 14.6 per cent. for women.

Rates for illness among students registered with the University Health Service were similar to those determined from the general practices. The rates for men were identical from both these sources: the difference in rates between the two sources for women students (14.3 per cent. UHS as opposed to $17 \cdot 7$ per cent. general practice) is not statistically significant $\left(\chi^{2}=1 \cdot 07\right.$, n.s.). In both the University Health Service and in the general practices psychological conditions were diagnosed significantly more often in women than in men students $\left(\chi^{2}=11 \cdot 81\right.$; $\mathbf{P}<0.001 ; 1$ d.f. for data from both sources combined).

The diagnostic categories into which the ill students were classified by their doctors are shown in Table III. Formal psychiatric illness accounted for less than half of the cases; most of these were neurotic disorders, among which anxiety states figured most prominently. The specific prevalence of formal psychiatric illness was 3.9 per cent. for men and 6.4 per cent. for women. The remaining categories comprise the "conspicuous psychiatric morbidity" group of Kessel (1960).

Of the 178 students who declared illness, 72 stated that they had consulted their doctor specifically for this. For 61 ( 85 per cent.) of these the doctor had diagnosed a psychological condition. A further seventy students who declared illness also stated that they had consulted their own doctor, though not specifically for an emotional complaint. For thirteen (19 per cent.) of these the doctor had diagnosed a psychological condition. The remaining 36 students who declared illness denied making a consultation for any complaint, six (19 per cent.) of these were recorded by their doctors as patients who had consulted during the survey year and were diagnosed as having a psychological condition. The overall relationship between diagnosed and declared illness is set out in Table IV (opposite).

Percentage agreement between doctors and students for both positive and negative reporting was 88 per cent. (i.e. in 1,365 out of 1,555 ), but students' statements confirmed only 47 per cent. ( 80 out of 178) of the doctors' diagnoses.

Of the factors cited in the review of the literature, 41 were tested to investigate their influence on the case rates for (a) medically-diagnosed psychiatric morbidity in the cohort ("diagnosed illness"), and

TABLE III

DISTRIBUTION OF MEDICALLY-DETECTED PSYCHIATRIC DISORDERS BY CLASSIFICATION EMPLOYED IN THIS STUDY

\begin{tabular}{|c|c|c|c|c|c|c|c|c|c|c|}
\hline \multicolumn{8}{|c|}{ Category } & \multirow{2}{*}{$\begin{array}{c}\text { Men } \\
\begin{array}{r}4 \\
2 \\
-\end{array}\end{array}$} & \multirow{2}{*}{ Women } & \multirow{2}{*}{$\begin{array}{c}\begin{array}{c}\text { All } \\
\text { Students }\end{array} \\
\begin{array}{c}5 \\
2 \\
1\end{array}\end{array}$} \\
\hline \multirow{6}{*}{ Formal Psychiatric Illness } & \multirow[t]{2}{*}{ Psychoois } & \multicolumn{3}{|c|}{$\begin{array}{l}\text { Schizophrenia } \\
\text { Paranoid psychosis } \\
\text { Epileptic psychotic episode }\end{array}$} & $\begin{array}{l}\cdots \\
\cdots \\
\cdots\end{array}$ & & $\begin{array}{l}\cdots \\
\cdots \\
\cdots \\
\end{array}$ & & & \\
\hline & & Total & . & . & . & . & $\cdots$ & 6 & 2 & 8 \\
\hline & \multirow[t]{2}{*}{ Neurosis } & \multicolumn{2}{|c|}{$\begin{array}{l}\text { Anxiety neurosis } \\
\text { Reactive depression } \\
\text { Hysteria .al ne. } \\
\text { Obsessional neurosis } \\
\text { Anorexia nervosa }\end{array}$} & $\begin{array}{l}\cdots \\
\cdots \\
\cdots \\
\cdots\end{array}$ & $\begin{array}{l}\cdots \\
\cdots \\
\cdots \\
\cdots\end{array}$ & $\begin{array}{l}\cdots \\
\cdots \\
\cdots \\
\cdots\end{array}$ & $\begin{array}{l}\cdots \\
\cdots \\
\cdots \\
\cdots\end{array}$ & $\begin{array}{r}14 \\
6 \\
2 \\
2 \\
-\end{array}$ & $\begin{array}{r}18 \\
10 \\
\frac{3}{2}\end{array}$ & $\begin{array}{r}32 \\
16 \\
5 \\
2 \\
2\end{array}$ \\
\hline & & Total & . & . & . & . & . & 24 & 33 & 57 \\
\hline & \multirow[t]{2}{*}{ Character Disorder } & \multicolumn{5}{|c|}{ 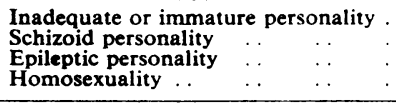 } & $\begin{array}{l}\cdots \\
\cdots \\
\cdots\end{array}$ & $\begin{array}{l}6 \\
\frac{1}{2}\end{array}$ & $\underline{2}$ & $\begin{array}{l}8 \\
1 \\
2\end{array}$ \\
\hline & & Total & . & $\cdots$ & . & . & $\ldots$ & 9 & 2 & 11 \\
\hline \multicolumn{8}{|c|}{ Psychological symptoms complained of by patient but not viewed by doctor as formal psychiatric illness } & 14 & 15 & 29 \\
\hline \multicolumn{8}{|c|}{$\begin{array}{l}\text { Abnormal features of behaviour noted by doctor as indicating psychological disturbance but not viewed } \\
\text { as formal psychiatric illness }\end{array}$} & 12 & 10 & 22 \\
\hline \multicolumn{3}{|c|}{ Psycho-physiological reactions and psychosomatic illness } & . & . & . & . & . & 23 & 22 & 45 \\
\hline \multicolumn{2}{|c|}{ All medically-detected psychological conditions } & . & . & . & . & $\ldots$ & . & 88 & 84 & 172 \\
\hline
\end{tabular}


TABLE IV

RELATIONSHIP BETWEEN DIAGNOSED AND DECLARED ILLNESS

\begin{tabular}{l|c|cc|c}
\hline \multicolumn{1}{|c|}{ Student reported Illness } & Yes & No & Total \\
\hline \begin{tabular}{l|cc} 
Doctor reported \\
Illness
\end{tabular} & Yes & 80 & 92 & 172 \\
& No & 98 & 1,285 & 1,383 \\
\cline { 2 - 5 } & Total & 178 & 1,377 & 1,555 \\
\hline
\end{tabular}

(b) self-declaration of emotional or nervous illness by the cohort ("declared illness"). The factors significantly associated with high case rates for psychiatric disorders are set out in Table V.
In Table $\mathrm{V}$ the factor of frequency of consultation last year refers to the number of times during the previous 12 months the student has personally consulted a doctor for any condition (i.e. the consultation rate); the number of past illnesses reported refers to the number of medical conditions set out on a checklist on the first questionnaire which the student marked as having experienced during the 5 years before entering the university; and the particular conditions reported refer to certain of these listed items. Each student on entry had rated his prowess in the work, sport, and extracurricular

TABLE V

FACTORS SIGNIFICANTLY ASSOCIATED WITH HIGH CASE RATES FOR PSYCHIATRIC DISORDERS

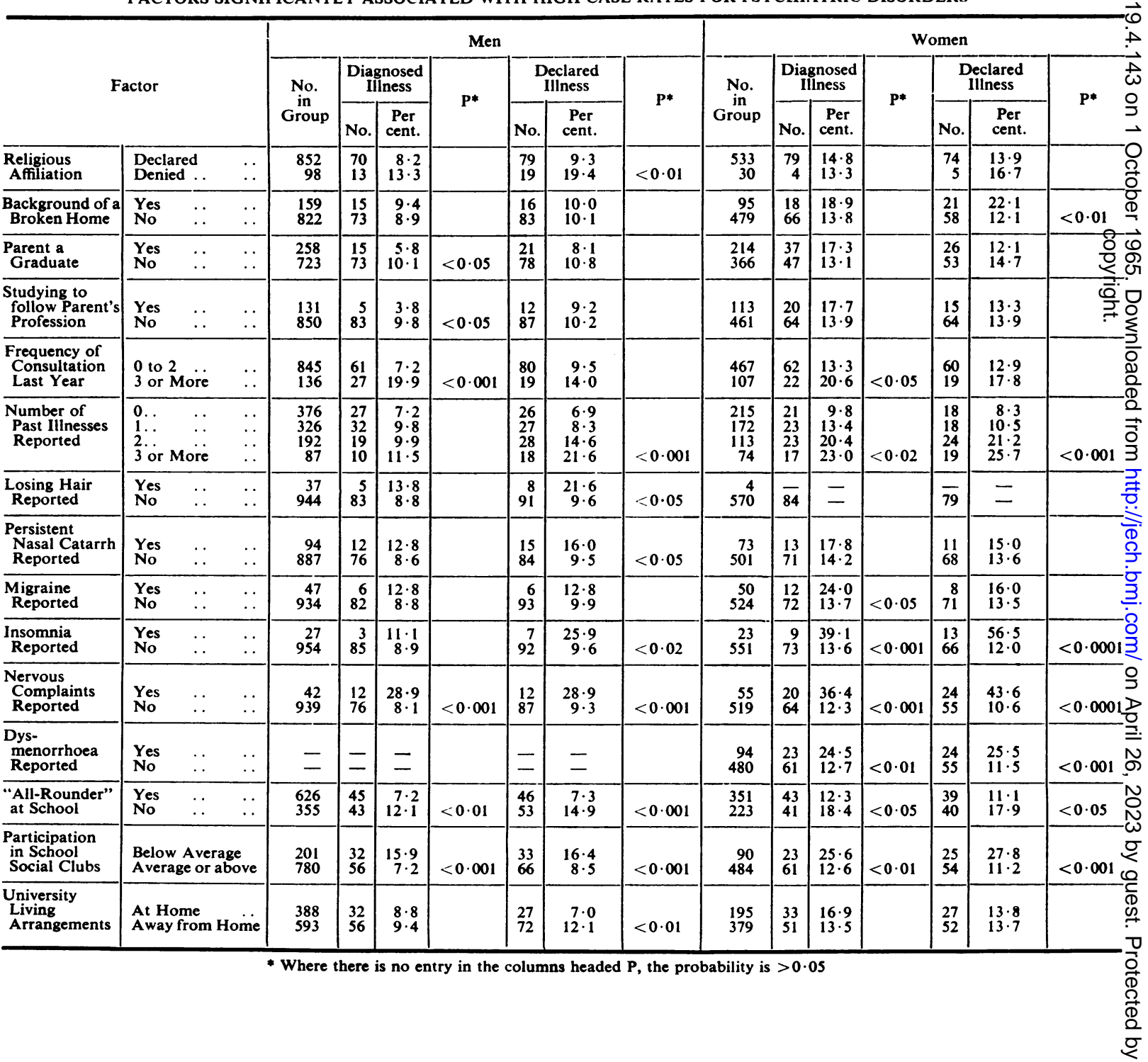


aspects of school life respectively as above average, average, or below average. An "all-rounder" was one whose self-ratings were average or above average in all three aspects; students who rated themselves as below average in any or all aspects of school life were classified as "non-all-rounders".

Overseas students as a group were not more prone to develop psychiatric disorders than were British students at Edinburgh. Among overseas students, however, the prevalence of psychiatric disorders was significantly high for men who did not have a western cultural background (because of small numbers cases of diagnosed and declared illness were grouped: $\left.\chi^{2}=6.79 ; P<0.01\right)$ and for men who were coloured $\left(\chi^{2}=6 \cdot 57 ; \mathrm{P}<0.02\right)$.

Conspicuously high case rates were found among the small numbers of students in whom the following factors were operative: ethnic factors (Nigerian men, American women, and German women cited); declaration of disharmony in the home (women); unfavourable attitudes to university entry; low selfrating of health; declaration of past history of urticaria, stammering, low back pain, and dyspepsia; studying music (women); flat-dwelling (women).

The factors that were not associated with psychiatric disorders were: age, social class, marital status, religious denomination, nationality, language, broken marriage, parents' attitude to student entering university, being grant-aided, financial strain on the family, financial hardship on the student, illness at school, certain past illnesses not listed above, type of school attended, public school education, entrance qualifications, faculty in which studying, type of course in which studying, previous experience of living away from home, commuting from home to university, residence during term.

\section{Discussion}

The method of approach to this study was determined largely by the concept of multiple causation of psychiatric disorders. The work was based on a preconception of the factors likely to be relevant to the causation of psychiatric disorders among university students, but it was clear from the literature on student mental illness that many factors were involved since, as Reid (1960) pointed out, we are dealing with both the predisposing characteristics of the individual and the precipitating effects of the immediate environment. The parameters of the inquiry set only one limitation on its scope. This was that the factors for investigation were those which could be readily identified at the point of entry of each student to the university. Fortuitous environmental stresses arising after entry to the university, which could not be anticipated by reference to the pre-university characteristics of students, fell outside the scope of this inquiry. Every factor that was cited in the literature as a likely concomitant of student stress and which was measurable on entry without direct examination of the student was included for investigation.

How far prevalence figures for medically-detected psychiatric morbidity among the cohort represent the real extent of psychiatric illness amongst students cannot be determined solely on the basis of consultations made with doctors. As Cooper, Brown, and Kalton (1962) have pointed out: "We do not know how consistently such disorders can be identified clinically by general practitioners with no special interest or training, nor to what extent doctors' individual attitudes may influence identification of psychiatric morbidity". The numbers of students on individual general practitioners' lists were too small to allow examination of the extent of variation between doctors in reporting psychiatric morbidity among the cohort. This study, however, by using the additional category "declared illness", provided a measure of ill-health reported by the students themselves which was independent of whether they had consulted a doctor or not. The findings on self-declaration of emotional illness suggest that several students were ill, yet their doctors did not know about it. This was because some had not consulted at all, some had consulted though not specifically for a psychiatric condition, and perhaps some had consulted with psychological symptoms, the significance of which were not immediately apparent to the doctor. The proportion of students who declared that they had been emotionally unwell and had not been identified as psychiatric cases by their doctors added a further $5 \cdot 8$ per cent. to the men and 6.9 per cent. to the women.

The hypotheses tested in this inquiry have provided the answers that the study was specifically designed to yield, namely, the significant characteristics of first-year university students who developed psychiatric disorders. Two cautionary notes apply to the interpretation of these results. First, it should be stressed that the establishment of statistically supported association does not necessarily imply any causal relationship between the factor studied and the student's subsequent mental ill-health, but it does indicate that students in whom such a factor was operative were significantly more likely to develop psychiatric disorders than those in whom the factor was not operative. The factors found to be associated with illness were not the causes but rather the outstanding attributes that influenced predisposition to illness. Secondly, the evidence that some factors were not the outstanding attributes that influenced pre- 
disposition to illness does not exclude the possibility that for some students any one of these "nonsignificant" factors may have been an over-riding source of stress, just as the presence of a "significant" factor in some students may have in no way influenced adversely their mental health. The associations, proven or not proven, relate to the group experience of all, but individual exceptions will occasionally occur. Similarly, the group experience of all refers to the students entering one university and their characteristics. Certain factors, for example disharmony in the home, unfavourable attitudes to university entry, being a woman living in a flat, being a woman music student, clearly influenced case rates among the very few students in whom these factors were operative, but because of the small numbers involved statistical associations could not be shown. The importance of these factors in provoking student distress must not be overlooked, for although they affect only a few entrants to this university, at another university of different student composition many more students might be affected by them and statistical associations between these factors and psychiatric disorders would be supported.

A knowledge of the characteristics of the illnessprone student are of particular value for two reasons: first, for identification of those who are likely to break down during their university course under ordinary circumstances because they are illnessprone, and secondly, for identification of those whose personal predisposition to illness renders them more likely than others to react unfavourably to any stressful environmental circumstances. Thus, the characteristics of illness-prone students relate directly to personal predisposition to psychiatric disorders and, indirectly, to the effects of the immediate environment in provoking psychological reactions.

The picture that emerges of the characteristics of students who are prone to develop psychiatric disorders shows that they can be identified and that there are definite main areas in which significant factors may be found.

Medical Factors.-These are the most noticeable. Illness-prone students can be readily identified from their medical histories and their consultation rates. These students are already known to their doctors: reference to their doctors would allow an illnessprone group to be delineated.

Educational Factors.- It is not important to know what examinations the students have passed or what type of school they attended: it is important to know about their capacity for general adjustment in the broader aspects of school life. Illness-prone students can be identified by their lack of participation in the non-work aspects of school curriculum. These students are known by their teachers to experience difficulty in adjusting to the general and social milieux of community life.

Personal Factors.-Two groups of illness-prone students can be identified by their personal characteristics. Women students are more prone to develop psychiatric disorders than men, and this study shows that women from broken or unhappy homes were particularly vulnerable in this respect. The second group comprises coloured students and those from a non-Western cultural background. Among overseas students, those who were confronted with the greatest ethnic and environmental contrasts were especially illness-prone.

One of the best ways of finding out which students are prone to develop psychiatric disorders is to ask them. Although this point may seem obvious, it is not generally recognized that such is the case. This study provides data in support of such a view. Significant proportions of those who reported on entry that they had had previous nervous complaints were subsequently found to have had a psychiatric disorder during the period of scrutiny. These findings support the opinion that students know their own psychiatric liabilities and, if asked, will declare them. Students' positive statements about their mental health seem reliable.

Most emphasis in this study has been placed on the factors in the student's background and experience thought likely to have a bearing on his subsequent mental health. The pattern of the characteristics of illness-prone students that this study has provided, however, suggests that for many, as Davy (1960) pointed out, "the scene is set long before the man or woman arrives at the university". This is important, because it seems that before entering a university these students had already a personal predisposition to psychiatric disorders. They presented with psychiatric disorders during their first year at the university, but the characteristics by which they are to be identified are the characteristics of illness-prone young people anywhere. Perhaps student problems are the problems of illness-prone individuals who happen to be students rather than problems that confront individuals because they are students. If this is indeed so, it would seem appropriate that those who are concerned with student mental health should lay more emphasis on the personalities of the students than on the environmental factors in the university.

This study provides information that is primarily relevant to the prevention of psychiatric disorders among students. The knowledge of the significant characteristics of students who are likely to develop 
psychiatric disorders is an essential step in designing a rational service for the prevention of student breakdown. If university physicians and others concerned with the welfare and happiness of students were aware of the factors that are the hallmark of predisposition to psychiatric disorders among students, it is possible that (a) such illness could be anticipated and offset by active "preventive vigilance" of the illness-prone student, and (b) that students identified by these characteristics should be earlier recognized as ill and their illness consequently modified by prompt intervention by the medical and welfare services.

\section{SUMmary}

An epidemiological study of the factors that influence the prevalence of psychiatric disorders among students of the University of Edinburgh was carried out. By prospective inquiry a total cohort of first-year students was identified on university entry, classified according to the presence or absence of each of various factors reported to have a bearing on the mental health of students, and followed for a complete academic year. Psychological illness that presented during this period was related back to the results of the initial classification, and in this way the factors that significantly influenced the prevalence of psychiatric disorders among the cohort were determined.

During the period of scrutiny of the 1,555 students who comprised the total entry cohort, two were admitted to a mental hospital, a further sixteen consulted a psychiatrist, and, in all, 172 (88 men, 84 women) who consulted a doctor were diagnosed as having a psychological condition. The prevalence rate for psychiatric disorders among the cohort for the one (academic) year was 9.0 per cent. for men and 14.6 per cent. for women.

Of all at risk, 178 ( 99 men, 78 women) declared by response to a questionnaire that during the period of scrutiny they had been "emotionally or nervously unwell". Expressed as percentages, the rates for self-declaration of illness among the cohort were $10 \cdot 1$ per cent. for men and $13 \cdot 8$ per cent. for women.

Hypotheses derived from factors cited in the literature were tested separately in respect of medically-diagnosed psychiatric morbidity in the cohort and self-declaration of emotional or nervous illness by the cohort. The findings of the significant attributes of students who are prone to develop psychiatric disorders show that they can be identified on entry to the university, and that there are definite main areas (medical, educational, and personal) in which significant factors may be found. This information has relevance to the design of a rational service for the prevention of student breakdown.

This study was made possible by the co-operation of 1,555 students, their 262 doctors, the teaching and administration staff of the University of Edinburgh, and the medical staffs of the psychiatric services in Edinburgh and the south-east region of Scotland. Thanks are especially due to $\mathrm{Dr}$ R. E. Verney and his colleagues of the University Health Service, and to Prof. G. M. Carstairs of the Department of Psychological Medicine, University of Edinburgh.

\section{REFERENCES}

Backett, E. M., Shaw, L. A., and Evans, J. C. G. (1953). Proc. roy. Soc. Med., 46, 707.

Carroll, H. A., and Jones, H. M. (1944). School and Society, 59, 270.

Cooper, B., Brown, A. C., and Kalton, G. (1962). J. Coll. gen. Pract., 5, 590.

Davy, B. W. (1957). Brit. med. J., $2,547$. (1960). Proc. roy. Soc. Med., 53, 764.

Gifford, P. (1961). Proc. Brit. Stud. Hlth Ass. (private circulation).

Grant, G. (1954). Brit. med. J., 2, 497.

Johnston, W. (1962). Queen's University of Belfast, Student Health Committee: "Report of Medical Officer for 1960-61".

Juel-Jensen, B. E. (1962). Brit. med. J., 2, 404.

Kessel, W. I. N. (1960). Brit. J. prev. soc. Med., 14, 16.

Malleson, N. (1954). Lancet, 1, 824.

London.

(1959a). Brit. med. J., 1, 1031.

(1959b). In "The Student and Mental Health.

Proc. I internat. Conf. on Student Mental Health,

Princeton, 1956", ed. D. H. Funkenstein, pp. 45, 61, 443. World Federation for Mental Health, Riverside Press, Cambridge, Mass.

(1961). "Conference on Student Mental Health".

World University Service, London.

Mechanic, D. (1961). J. chron. Dis., 15, 189.

Parnell, R. W. (1947). Lancet, $2,939$.

Pemberton, J. (1948). Brit. med. J., 1, 490.

Read, J. C. (1954). Lancet, 1, 822.

Reid, D. D. (1960). "Epidemiological Methods in the Study of Mental Disorders". Publ. Hlth Papers, No. 2. World Health Organization, Geneva.

Sinclair-Gieben, A. H. C. (1961). "Conference on Student Mental Health". World University Service, London.

Snyder, B. (1962). "The Psychiatric Service". Report of the Committee on Educational Policy. Massachusetts Institute of Technology.

Still, R. J. (1961). "Conference on Student Mental Health". Campbell Hall, London.

Verney, R. E. (1961). "Morbidity Rates". University of Edinburgh, Student Health Service (mimeo).

and Robertson, R. F. (1948). Lancet, 1, 251. 